\title{
Pengaruh Sistem Pengendalian Intern Pemerintah (SPIP) Terhadap Pencegahan Fraud dalam Pengelolaan Dana Desa dengan Akuntabilitas Sebagai Variabel Mediasi
}

\author{
Sri Ayem*, Kirana Feby Kusumasari \\ Universitas Sarjanawiyata Tamansiswa, Yogyakarta, Indonesia \\ * sriayemfeust@gmail.com
}

\author{
Riwayat Artikel: \\ Tanggal diajukan: \\ 24 Juni 2020 \\ Tanggal diterima: \\ 28 Agustus 2020 \\ Tanggal dipublikasi: \\ 31 Agustus 2020
}

Kata kunci: Sistem Pengendalian Intern Pemerintah, Fraud, Akuntabilitas, Dana Desa

\begin{abstract}
Abstrak
Penelitian ini bertujuan untuk mengetahui pengaruh Sistem Pengendalian Intern Pemeritah terhadap fraud dengan akuntabilitas sebagai variabel mediasi. Penelitian ini mengambil sampel di kecamatan Ngaglik dan Ngemplak. Pengumpulan data dilakukan secara langsung dengan menggunakan kuesioner. Populasi dalam penelitian ini adalah kepala desa atau PJ kadus, bagian keuangan yaitu kaur keuangan atau staf keuangan dan beberapa sekertaris dan staf umum. Dari penyebaran kuesioner didapatkan 30 sample. Teknik analisis data pada penelitian ini menggunakan teknik regresi linear berganda dan analisis regresi moderasi dengan bantuan program SPSS (Statistic Package for Social Science) versi 18.0. Hasil peneitian ini menunjukkan bahwa Sistem Pengendalian Intern Pemerintah berpengaruh terhadap Akuntabilitas sementara Sistem Pengendalian Internal Pemerintah tidak berpengaruh terhadap Fraud dan Sistem Pengendalian Intern Pemerintah tidak berpengaruh terhadap fraud dengan Akuntabilitas sebagai variabel mediasi.
\end{abstract}

\section{Pengutipan:}

Ayem, S., \& Kusumasari, K. F. (2020). Pengaruh Sistem Pengendalian Intern Pemerintah (SPIP) terhadap Pencegahan Fraud dalam Pengelolaan Dana Desa dengan Akuntabilitas Sebagai Variabel Mediasi. Jurnal IImiah Akuntansi dan Humanika, 10(2), 160-169

Keywords: Government Internal Control System, Fraud, Accountability, Village Funds

\begin{abstract}
This study aims to determine the effect of internal control systems for fraud with accountability as a mediation variable. This study took samples in Ngaglik and Ngemplak sub-districts. Data collection is done directly by using questionnaires. The population in this study is the head of the village or PJ Kadus, the financial section of financial vows or financial staff and some of the Secretary and General Staff. From the survey spread obtained 30 samples. The data analysis techniques in this study used double linear regression techniques and the moderated regression analysis with the help of SPSS (Statistic Package for Social Science) program version 18.0. The results showed that the government internal control system was influential about accountability while the government's internal control system had no effect on Fraud and the government's internal control system had no effect on fraud with accountability as a mediation variable.
\end{abstract}

\section{Pendahuluan}

Undang-Undang Desa telah menjadikan desa sebagai awal mula pembangunan dan peningkatan kesejahteraan masyarakat. Desa diberikan sumber dana dan juga kewenangan agar dapat mengelola potensi yang dimiliki sehingga diharapkan dapat meningkatkan ekonomi dan kesejahteraan masyarakat.

Menurut Undang-Undang Nomor 6 Tahun 2014 tentang Desa, desa ialah kesatuan masyarakat hukum yang memili batasan wilayah yang berwenang untuk mengatur dan mengurus urusan pemerintahan, kepentingan masyarakat setempat berdasarkan prakarsa masyarakat, hak asal usul, dan/atau hak tradisional yang diakui dan dihormati dalam sistem 
pemerintahan Negara Kesatuan Republik Indonesia. (Undang Undang Nomor 6 Tahun 2014 tentang Desa, 2014)

Menurut Peraturan Pemerintah Nomor 8 Tahun 2016 tentang Dana Desa yang bersumber dari APBN, Pasal 1, ayat 2: Dana Desa adalah Dana yang bersumber dari Anggaran Pendapatan dan Belanja Negara yang diperuntukkan bagi Desa yang ditransfer melalui Anggaran Pendapatan dan Belanja Daerah Kabupaten/Kota dan digunakan untuk membiayai penyelenggaraan pemerintahan, pelaksanaan pembangunan, pembinaan kemasyarakatan, dan pemberdayaan masyarakat. (Peraturan Pemerintah Nomor 8 Tahun 2016 tentang Dana Desa yang Bersumber dari Anggaran Pendapatan dan Belanja Negara, 2016)

Sistem Pengendalian Intern yang merupakan proses integral pada tindakan dan kegiatan yang dilakukan secara terus menerus oleh pimpinan dan seluruh pegawai untuk memberikan keyakinan memadai atas tercapainya tujuan organisasi melalui kegiatan yang efektif dan efisien, keandalan pelaporan keuangan, pengamanan aset negara, dan ketaatan terhadap peraturan perundang-undangan. Menurut PP Nomor 60 Tahun 2008 tentang Sistem Pengendalian Intern Pemerintah, SPIP adalah: "Proses yang integral pada tindakan dan kegiatan yang dilakukan secara terus menerus oleh pimpinan dan seluruh pegawai untuk memberikan keyakinan memadai atas tercapainya tujuan organisasi melalui kegiatan yang efektif dan efisien, keandalan pelaporan keuangan, pengamanan aset negara, dan ketaatan terhadap peraturan perundang-undangan." (Peraturan Pemerintah 60 Tahun 2008 tentang Sisitem Pengendalian Intern Pemerintah, 2008)

Akuntabilitas Kinerja adalah perwujudan kewajiban suatu instansi pemerintah untuk mempertanggungjawabkan keberhasilan/kegagalan pelaksanaan Program dan Kegiatan yang telah diamanatkan para pemangku kepentingan dalam rangka mencapai misi organisasi secara terukur dengan sasaran/target Kinerja yang telah ditetapkan melalui laporan kinerja instansi pemerintah yang disusun secara periodik. (Peraturan Pemerintah Nomor 29 Tahun 2014 tentang Sistem Akuntabilitas Kinerja Instansi Pemerintah, 2014)

Desa yang di masa lalu lebih banyak menjadi objek kebijakan dan pelaksanaan pembangunan, kini memiliki kewenangan dan kesempatan lebih luas untuk merumuskan kebijakan dan melaksanakan pembangunannya sendiri. Dalam pelaksanaan UndangUndang Desa, berbagai regulasi turunan undang-undang telah diterbitkan untuk mengatur berbagai hal agar pembangunan Desa dapat berjalan sebagaimana amanat Undang-Undang Desa. Regulasi tersebut tertuang di dalam berbagai tingkatan, dimulai dari Peraturan Pemerintah, Peraturan Menteri-menteri terkait (Peraturan Menteri Dalam Negeri, Peraturan Menteri Desa, Pembangunan Daerah Tertinggal dan Transmigrasi, dan Peraturan Menteri Keuangan), dan juga peraturan pelengkap yang diterbitkan oleh daerah.

Pemerintah sudah mengucurkan dana desa sebanyak Rp 127,74 triliun sejak pertama kali digelontorkan pada 2015. Desa yang sudah menerima dana tersebut 74.910 dengan rincian pada 2015 sebesar Rp 20,76 triliun, 2016 sebesar Rp 49,98 triliun, 2017 sebesar Rp 60 triliun, 2018 sebesar Rp 60 triliun, 2019 sebesar 70 triliun dan 2020 sebesar 72 triliun. (Kemenkeu, 2020)

Jumlah alokasi dana desa tersebut membuat KPK memiliki tugas yang cukup besar dalam aktivitas pengawasannya, karena semakin besar dana yang diberikan akan membuat kemungkinan besar pula penyalahgunaannya. Hal tersebut dapat dibuktikan dengan maraknya pemberitaan di berbagai media terkait dengan penyalahgunaan dana desa, bahkan menurut Presiden Jokowi dari sekitar 74.910 desa yang menerima dana desa, di tahun 2017 kurang lebih ada 900 desa yang mempunyai masalah, kepala desanya ditangkap karena menyelewengkan dana desa. (Riyandi, 2017)

Bahkan pada awal semester 2018 masih tercatat 29 orang kepala desa menjadi tersangka kasus korupsi dana desa. Kasus korupsi merupakan salah satu dari bentuk kecurangan, kecurangan dapat terjadi karena ada faktor penyebab yang tidak terlepas dari konsep segitiga kecurangan (fraud triangle) yaitu tekanan (pressure), kesempatan (opportunity) dan rasionalisasi (rationalization). Kecurangan yaitu suatu tindakan penyimpangan atau perbuatan melanggar hukum yang dilakukan secara sengaja untuk tujuan tertentu. Menipu atau memberikan yang keliru untuk keuntungan pribadi atau 
kelompok secara tidak adil, baik secara langsung maupun tidak langsungdapat merugikan pihak lain.

Dengan adanya kondisi yang memungkinkan terjadinya potensi penyalahgunaan dana desa baik dari sisi salah prosedur potensi fraud dana desa rawan sekali terjadi.

Penulis dalam melakukan penelitian mengambil rujukan dari beberapa penelitian terdahulu diantaranya yang dilakukan oleh (Widyatama \& Novita, 2017) dengan judul "Pengaruh Kompetensi dan Sistem Pengendalian Internal Terhadap Akuntabilitas Pemerintah Desa dalam Mengelola Alokasi Dana Desa (ADD)" hasil dari penelitian ini menunjukkan bahwa variabel sistem pengendalian memberikan pengaruh positif terhadap akuntabilitas dalam pengelolaan dana desa.

Pada penelitian (Ina Mutmainah*, 2017) dengan judul "Penerapan Akuntabilitas Pengelolaan Dana Desa Dan Sistem Pengendalian Intern Pemerintah (SPIP)" hasil dari penelitian itu menunjukkan bahwa sistem pengendalian intern pemerintah tidak berpengaruh signifikan terhadap pengelolaan dana desa. Penulis pun mengambil rujukan dari penelitian yang dilakukan oleh (Atmadja et al., 2015) yang berjudul "Pencegahan Fraud Dalam Pengelolaan Keuangan Desa" hasil dari penelitian itu menunjukkan sistem pengendalian internal berpengaruh terhadap pencegahan fraud dalam pengelolaan dana desa.

Penelitian ini merupakan replikasi dari penelitian sebelumnya yang dilakukan oleh (Widyatama \& Novita, 2017) dengan judul "Pengaruh Kompetensi dan Sistem Pengendalian Internal Terhadap Akuntabilitas Pemerintah Desa dalam Mengelola Alokasi Dana Desa (ADD)" yang menjadi pembeda yaitu peneliti tidak menggunakan variabel penelitian Kompetensi, akuntabilitas menjadi variabel mediasi dan menambahkan fraud sebagai variabel Y. Sehingga penelitian ini menggambil judul: "Sistem Pengendalian Intern Pemerintah (SPIP) Terhadap Pencegahan Fraud dalam Pengelolaan Dana Desa Dengan Akuntabilitas sebagai Variabel Mediasi"

\section{Kajian Teori}

Teori Keagenan (agency theory)

Dicetuskan oleh Jensen dan Meckling (1976) menjelaskan bahwa teori keagenan merupakan teori mengenai perbedaan kepentingan antara prinsipal dan agen. Dalam penelitian ini kepala desa maupun perangkatnya bertindak sebagai agen dan masyarakat sebagai principal.

\section{Teori Tindakan Komunikatif (The Theory of Communicative Action)}

Tindakan komunikatif yang dimaksud yaitu tindakan yang mengarahkan setiap tindakan menjadi tindakan yang rasional dan berorientasi kepada kesepahaman, persetujuan dan rasa saling mengerti.

\section{Sistem Pengendalian Intern Pemerintah (SPIP)}

Menurut PP Nomor 60 Tahun 2008 tentang Sistem Pengendalian Intern Pemerintah, SPIP adalah: "Proses yang integral pada tindakan dan kegiatan yang dilakukan secara terus menerus oleh pimpinan dan seluruh pegawai untuk memberikan keyakinan memadai atas tercapainya tujuan organisasi melalui kegiatan yang efektif dan efisien, keandalan pelaporan keuangan, pengamanan aset negara, dan ketaatan terhadap peraturan perundangundangan." (PP 2008)

\section{Kecurangan (Fraud)}

Kecurangan yaitu suatu tindakan penyimpangan atau perbuatan melanggar hukum yang dilakukan secara sengaja untuk tujuan tertentu. Menipu atau memberikan yang keliru untuk keuntungan pribadi atau kelompok secara tidak adil, baik secara langsung maupun tidak langsungdapat merugikan pihak lain.

\section{Sistem Pengendalian Intern Pemerintah Terhadap Akuntabilitas}

Sistem pengendalian internal pemerintah dan juga akuntabilitas telah diatur pada Peraturan Pemerintah Nomor 60 Tahun 2008 yang menyatakan bahwa aparat pengawasan 
intern pemerintah melakukan pengawasan intern atas penyelenggaraan tugas dan fungsi instansi pemerintah termasuk akuntabilitas keuangan negara dan pembinaan penyelenggaraan SPIP.

Akuntabilitas sebagai pemegang kewajiban untuk memberikan pertanggungjawaban, menyajikan, melaporkan, dan mengungkapkan segala aktivitas dan kegiatan yang menjadi tanggung jawabnya kepada pihak pemberi amanah yang memiliki hak untuk meminta pertanggungjawaban tersebut.

Sistem pengendalian intern ternyata dapat tidak berpengaruh terhadap akuntabilitas pengelolaan keuangan daerah seperti pada penelitian yang dilakukan oleh (Melisha, 2018) hal ini dikarenakan karena tidak dilakukannya penentuan batas terhadap risiko, penentuan toleransi, belum menerapkan pengendalian internal, manajemen risiko dan juga sistem informasi untuk melaksanakan tanggungjawab yang tidak dilaksanakan, tetapi pada penelitian yang dilakukan oleh (Widyatama \& Novita, 2017) dan juga (Yudianto \& Sugiarti, 2017) unsur unsur pengendaian dilakukan dengan tersturktur dan terus menerus sehingga sistem pengendalian memberikan pengaruh positif terhadap akuntabilitas pengelolaan dana desa. Maka dengan berjalanya sistem pengendalian internal yang terus menerus diharapkan akan menghasilkan akuntabilitas pada penyampaian laporan keuangan. Berdasalkan hal tersebut maka dirumuskan hipotesis sebagai berikut:

\section{$\mathrm{H}_{1}$ : Sistem Pengendalian Intern Pemerintah Berpegaruh Positif Terhadap Akuntabilitas.}

\section{Sistem Pengendalian Intern Pemerintah Terhadap Fraud}

Sistem pengendalian intern pemerintah perlu dilakukan terus menerus dengan kelima unsur yang saling berkaitan. Kelima unsur ini saling menopang satu sama lain, jika salah satu unsur tidak terlaksana maka hal ini menimbulkan pertanyaan apakah sistem pengendalian pengendalian intern pemerintah cukup efektif untuk dapat mengendalikan fraud. Seperti pada ada penelitian yang dilakukan oleh (Atmadja et al., 2015) yang kelima unsur sudah dilakukan dengan baik sehingga sistem pengendalian internal berpengaruh terhadap pencegahan fraud dalam pengelolaan dana desa. Tetapi hal ini tidak sejalan dengan penelitian yang dilakukan oleh (Buleleng et al., 2017) yang menghasilkan bahwa terdapat pengaruh yang negatif sistem pengendalian internal terhadap kecenderungan terjadinya kecurangan (fraud). Berdasalkan hal tersebut maka dirumuskan hipotesis sebagai berikut:

\section{$\mathrm{H}_{2}$ : Sistem Pengendalian Intern Pemerintah Berpengaruh Negatif Terhadap Fraud}

\section{Sistem Pengendalian Internal Pemerintah Terhadap Fraud dengan Akuntabilitas Sebagai Variabel Mediasi}

Dengan adanya penelitian sistem pengendalian internal terhadap fraud dan juga sistem pengendalian internal terhadap akuntabilitas maka pada penelitian ini sistem pengendalian internal terhadap fraud dipengaruhi dengan adanya variabel mediasi yang berupa akuntabilitas, akuntabilitas diharapkan dapat mencegah terjadinya fraud dilingkungan pemerintahan desa.

Pada penelitian yang dilakukan oleh (Ayu et al., 2017) akuntabilitas berpengaruh negatif dan signifikan terhadap potensi fraud hal ini dikarenakan pengelolaan keuangan direncanakan tidak terbuka sehingga tidak dapat dipertanggungjawabkan secara administrasi, teknis dan hukum. Tetapi hal tersebut tidak terjadi oleh penelitian yang dilakukan oleh (Adi et al., 2019) informasi tentang keuangan desa yang dilakukan secara transparan sehingga menuntut dilakukannya pertanggungjawaban maka pada penelitian tersebut akuntabilitas berpengaruh positif pada pencegahan fraud. Maka berdasarkan beberapa hal tersebut dirumuskan hipotesis sebagai berikut:

\section{$\mathrm{H}_{3}$ : Sistem Pengendalian Internal Pemerintah Berpengaruh Positif Terhadap Fraud dengan Akuntabilitas Sebegai Variabel Mediasi}




\section{Metode}

Uji Validitas

Suatu kuesioner dikatakan valid jika pertanyaan pada kuesioner mampu untuk mengungkapkan sesuatu yang akan diukur oleh kuesioner tersebut. Jika nilai $r$ hitung atau pearson correlation lebih besar daripada nilai $r$ tabel dan nilai sig. (2-tailed) berada di bawah nilai alpha yaitu 0,05 $(5 \%)$, maka item atau butir pernyataan tersebut dinyatakan valid (Ghozali, 2016). Dari semua point pertanyaan memiliki nilai $r$ hitung lebih besar dari $r$ table sehingga semua point dinyatakan valid.

\section{Uji Reliabilitas}

Uji reliabilitas dilakukan dengan bantuan menggunakan Softare Microsoft Excel 2010 dan diolah dengan menggunkan SPSS versi 18.0. berdasarkan hasil output yang tersaji dalam tabel 4.3 dapat disimpulkan baha semua variabel dinyatakan reliabel. Hal ini dibuktikan dengan nilai Cronbach's Alpha yang lebih besar dari 0,60.

Tabel 1. Uji reliabilitas

\begin{tabular}{llrl}
\hline No & Variabel & $\begin{array}{r}\text { Cronbach's } \\
\text { Alpha }\end{array}$ & Keterangan \\
\hline 1. & SPIP & 0,890 & Reliabel \\
2. & Fraud & 0,836 & Reliabel \\
3. & Akuntablitas & 0,958 & Reliabel \\
\hline
\end{tabular}

\section{Statistik Deskriptif}

Pengujian statistik deskriptif dilakukan dengan menggunakan program SPSS versi 18.0, berikut ini adalah hasil dari pengujian statistik deskriptif:

\section{Statistics}

\begin{tabular}{lrrr}
\hline & SPIP & Fraud & $\begin{array}{c}\text { Akuntabilita } \\
\text { S }\end{array}$ \\
\hline N $\quad$ Valid & 30 & 30 & 30 \\
Missing & 0 & 0 & 0 \\
Mean & 40,07 & 27,70 & 34,30 \\
Std. Error of & 1,037 &, 943 & 1,114 \\
Mean & & & 35,50 \\
Median & 41,00 & 29,00 & 32 \\
Mode & 39 & $28^{a}$ & 6,103 \\
Std. Deviation & 5,681 & 5,167 & 37,252 \\
Variance & 32,271 & 26,700 & 32 \\
Range & 26 & 18 & 8 \\
Minimum & 21 & 16 & 40 \\
Maximum & \multicolumn{4}{c}{34} & \\
Multiple modes exist. The smallest value is shown \\
Sumber: Data primer yang diolah 2020
\end{tabular}

Berdasarkan table diatas dapat diketahui jumlah data $(N)$ sebanyak 30 . SPIP memiliki rata-rata 42,03 dengan standar deviasi sebesar 3,996. Rata-rata fraud 36,70 dengan standar deviasi sebesar 3,405. Rata-rata akuntabilitas 25,53 dengan standar deviasi sebesar4,659. 


\section{Hasil Uji Normalitas}

Uji normalitas data bertujuan untuk menguji apakah dalam model regresi, variabel penggangu atau residual memiliki distribusinormal. Pengujian normalitas data dengan 2 persamaan menggunakan uji statistik non parametik Kolmogrov-Smirnov (K-S) dengan bantuan SPSS versi 18.0. tabel dibawah ini menyajikan mengenai hasil pengujian normalitas data:

\begin{tabular}{lll}
\multicolumn{2}{c}{ One-Sample Kolmogorov-Smirnov Test } \\
& $\begin{array}{c}\text { Unstandardized } \\
\text { Residual }\end{array}$ \\
\hline $\mathrm{N}$ & 30 \\
Normal Parameters & $\begin{array}{c}\text { M,b } \\
\text { Mean }\end{array}$ &, 0000000 \\
& Std. Deviation & 4,56942047 \\
Most Extreme Differences & Absolute &, 199 \\
& Positive &, 163 \\
& Negative &,- 199 \\
Kolmogorov-Smirnov Z & 1,090 \\
Asymp. Sig. (2-tailed) &, 186 \\
\hline a. Test distribution is Normal. & \\
b. Calculated from data. & \\
Sumber: Data primer yang diolah 2020 &
\end{tabular}

Dari hasil uji normalitas menggunakan metode Kolomogrov Sminov didapatkan hasil signifikansi dari uji normalitas sebesar 0,722 dimana hasil tersebut lebih besar dari taraf signifikansi 0,05 . Sehingga disimpulkan bahwa uji tes normalitas pada penelitian ini adalah terdistribusi normal.

\section{Hasil Uji Multikolinieritas}

Untuk mendeteksi ada tidaknya multikolinieritas dapat dilihat pada nilai Tolerance dan VIF. Apabila nilai tolerance diatas 0,1 dan nilai VIF dibaah 10 maka tidak terjadi multikolinoeritas. Hasil uji multikolinoeritas dapat dilihat pada tabel berikut ini.

\section{Coefficients $^{a}$}

\begin{tabular}{|c|c|c|c|c|c|c|c|c|}
\hline & \multirow[t]{2}{*}{ Model } & \multicolumn{2}{|c|}{$\begin{array}{c}\text { Unstandardized } \\
\text { Coefficients }\end{array}$} & $\begin{array}{l}\text { Standardized } \\
\text { Coefficients }\end{array}$ & \multirow[b]{2}{*}{$\mathrm{t}$} & \multirow[b]{2}{*}{ Sig. } & \multicolumn{2}{|c|}{$\begin{array}{c}\text { Collinearity } \\
\text { Statistics }\end{array}$} \\
\hline & & $\mathrm{B}$ & Std. Error & Beta & & & Tolerance & VIF \\
\hline \multirow[t]{3}{*}{1} & (Constant) & 10,935 & 6,614 & & 1,653 & 110 & & \\
\hline & Total X & ,166 & ,179 & 183 & ,931 & ,360 & ,750 & 1,333 \\
\hline & Total Z & 294 & , 166 & ,348 & 1,771 & ,088 &, 750 & 1,333 \\
\hline
\end{tabular}

Dependent Variable: Total $Y$

Sumber: Data primer yang diolah 2020

Variabel SPIPmemiliki nilai tolerance sebesar 0,919 dan nilai VIF sebesar 1,088. Variabel Akuntabilitas memiliki nilai tolerance sebesar 0,919 dan nilai VIF sebesar 1,088.

Sehingga disimpulkan bahwa uji tes multikolinieritas pada penelitian ini pervariabel nilai tolerance diatas 0,1 dan nilai VIF dibawah 10 maka artinya tidak terjadi multikolinieritas.

Hasil Uji Heteroskesdatisitas

\begin{tabular}{|c|c|c|c|c|c|c|}
\hline \multicolumn{7}{|c|}{ Coefficients $^{\mathrm{a}}$} \\
\hline & \multirow[t]{2}{*}{ Model } & \multicolumn{2}{|c|}{$\begin{array}{l}\text { Unstandardized } \\
\text { Coefficients }\end{array}$} & $\begin{array}{l}\text { Standardized } \\
\text { Coefficients }\end{array}$ & \multirow[b]{2}{*}{$\mathrm{t}$} & \multirow[b]{2}{*}{ Sig. } \\
\hline & & B & Std. Error & Beta & & \\
\hline \multirow[t]{3}{*}{1} & (Constant) & $-1,959$ & 4,303 & &,- 455 & ,653 \\
\hline & Total X & ,102 & ,116 & 189 & 875 & ,389 \\
\hline & Total Z &, 036 &, 108 &, 071 & ,330 & ,744 \\
\hline
\end{tabular}

Sumber: Data primer yang diolah 2020

Berdasarkan tabel diatas hasil uji glesjer dapat dairtikan bahwa tidak terdapat gejala heteroskedastisitas. Hal ini didukung dengan nilai signifikansi dari masing-masing variabel 
yang berada diatas 0,05 . Berdasarkan table nilai signiikansi dari SPIP sebesar 0,389 dan nilai signiikansi dari akuntabilitas sebesar 0,744.

\section{Pengujian Hipotesis}

Uji Simultan (F)

Uji simultan ini digunakan untuk menguji variabel bebas secara berama-sama mempengeruhi variabel terikat. Hasil uji $\mathrm{F}$ disajikan pada table dibawah ini:

ANOVA $^{b}$

\begin{tabular}{|c|c|c|c|c|c|c|}
\hline \multicolumn{2}{|r|}{ Model } & $\begin{array}{c}\text { Sum of } \\
\text { Squares }\end{array}$ & df & Mean Square & \multirow{2}{*}{$\frac{F}{3,763}$} & \multirow{2}{*}{$\frac{\text { Sig. }}{, 036^{\circ}}$} \\
\hline 1 & Regression & 168,792 & 2 & 84,396 & & \\
\hline & Residual & 605,508 & 27 & 22,426 & & \\
\hline & Total & 774,300 & 29 & & & \\
\hline
\end{tabular}

a. Predictors: (Constant), Total Z, Total X

b. Dependent Variable: Total $Y$

Berdasarkan hasil pengolahan data di atas menunjukkan nilai Fhitung sebesar 3,763 dan sig 0,000 lebih kecil dari 5\%. Selanjutnya, membandingkanFhitung dengan Ftabel. (pada df 0,05 diperoleh nilai Ftabel $=3,35)$ sehingga Fhitung $>$ Ftabel $(3,763>3,35)$, maka dapat di simpulkan bahwa Akuntabilitas dan SPIP secara menyeluruh berpengaruh terhadap Fraud.

\begin{tabular}{llrrrrr}
\multicolumn{8}{c}{ ANOVA $^{\mathbf{b}}$} \\
Model & Sum of & & & & \\
& & Squares & Df & Mean Square & F & Sig. \\
\hline 1 & Regression & 354,026 & 2 & 177,013 & 6,581 &, $0^{\text {a }}$ \\
& Residual & 726,274 & 27 & 26,899 & & \\
& Total & 1080,300 & 29 & & & \\
\hline
\end{tabular}

a. Predictors: (Constant), Total Y, Total $\mathrm{X}$

b. Dependent Variable: Total Z

Berdasarkan hasil pengolahan data di atas menunjukkan nilai $F_{\text {hitung }}$ sebesar 6,581 dan sig 0,000 lebih kecil dari $5 \%$. Selanjutnya, membandingkanFhitung dengan $\mathrm{F}_{\text {tabel. }}$ (pada $\mathrm{df}$ $0,05$ diperoleh nilai Ftabel $=3,35)$ sehingga Fhitung $>$ Ftabel $(6,581>3,35)$, maka dapat di simpulkan bahwa Fraud dan SPIP secara menyeluruh berpengaruh terhadap Akuntabilitas.

$\underline{\text { Uji Parsial }(T)}$

\begin{tabular}{|c|c|c|c|c|c|c|}
\hline \multicolumn{7}{|c|}{ Coefficients $^{a}$} \\
\hline & \multirow[t]{2}{*}{ Model } & \multicolumn{2}{|c|}{$\begin{array}{l}\text { Unstandardized } \\
\text { Coefficients }\end{array}$} & $\begin{array}{c}\text { Standardized } \\
\text { Coefficients }\end{array}$ & \multirow[b]{2}{*}{$\mathrm{t}$} & \multirow[b]{2}{*}{ Sig. } \\
\hline & & $\mathrm{B}$ & Std. Error & Beta & & \\
\hline \multirow[t]{3}{*}{1} & (Constant & 10,935 & 6,614 & & 1,653 &, 110 \\
\hline & Total X & 166 & 179 & 183 & ,931 & 360 \\
\hline & Total Z & 294 & , 166 & 348 & 1,771 & ,088 \\
\hline
\end{tabular}

Tabel diatas merupakan uji persial substruktur yang menunjukkan pengaruh variabel SPIP (X) dan akuntabilitas (Z) terhadap Fraud (Y).

Berdasarkan tabel diatas dapat diketahui nilai signifikansi SPIP lebih besar dari probabilitas yaitu 0,360 >0,05 dengan nilai $t_{\text {hitung }}$ lebih kecil dari $t_{\text {tabe }}$ yaitu 0,931<2,051.

Dengan demikian maka tidak ada pengaruh variabel SPIP terhadap Fraud.

Berdasarkan tabel diatas dapat diketahui nilai signifikansi akuntabilitas lebih besar dari probabilitas yaitu 0,088 $>0,05$ dengan nilai thitung lebih kecil dari tabel yaitu 1,771<2,051. Dengan demikian maka tidak ada pengaruh variabel akuntabilitas terhadap Fraud. 


\section{Coefficients $^{a}$}

\begin{tabular}{llrrrrr}
\hline \multirow{2}{*}{ Model } & \multicolumn{2}{c}{$\begin{array}{c}\text { Unstandardized } \\
\text { Coefficients }\end{array}$} & \multicolumn{2}{c}{$\begin{array}{c}\text { Standardized } \\
\text { Coefficients }\end{array}$} & \\
\cline { 2 - 5 } & \multicolumn{1}{c}{ B } & Std. Error & Beta & \multicolumn{1}{c}{ t } & \multicolumn{1}{c}{ Sig. } \\
\hline 1 (Constant) & 7,598 & 7,459 & & 1,019 &, 317 \\
Total X &, 422 &, 181 &, 393 & 2,327 &, 028 \\
Total Y &, 353 &, 200 &, 299 & 1,771 &, 088 \\
\hline
\end{tabular}

a. Dependent Variable: Total Z

Tabel 4.15 diatas merupakan uji persial substruktur yang menunjukkan pengaruh variabel SPIP (X) dan Fraud (Y) terhadap akuntabilitas (Z).

Berdasarkan tabel diatas dapat diketahui nilai signifikansi SPIP lebih kecil dari probabilitas yaitu 0,028 $>0,05$ dengan nilai $t_{\text {hitung }}$ lebih besar dari $t_{\text {tabel }}$ yaitu 2,327 $>2,051$. Dengan demikian maka terdapat pengaruh variabel SPIP terhadap Akutabilitas.

Berdasarkan tabel diatas dapat diketahui nilai signifikansi fraud lebih besar dari probabilitas yaitu 0,088 $>0,05$ dengan nilai thitung lebih kecil dari tabel yaitu 1,771<2,051. Dengan demikian maka tidak ada pengaruh variabel fraud terhadap Akuntabilitas.

Koefisien Jalur

Diagram Jalur

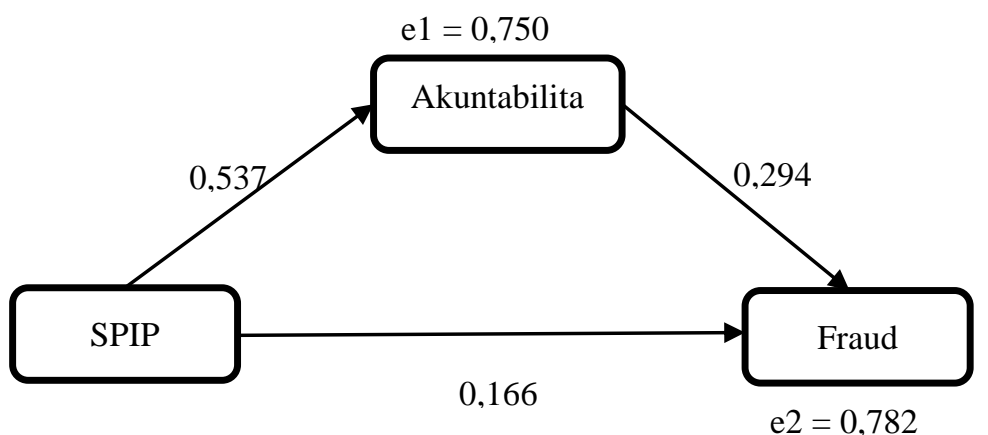

Dilihat dari nilai signifikansi SPIP berpengaruh terhadap akuntabilitas, SPIP berpengaruh terhadap fraud dan akuntabilitas berpengaruh terhadap fraud. Sehinga hasil analisis diatas menunjukkan bahwa SPIP dapat berpengaruh langsung terhadap Fraud dan dapat juga berpengaruh tidak langsung melalui akuntabilitas sebagai variabel mediasi.

Besarnya pengaruh langsung yaitu 0,166 , sedangkan besarnya pengaruh tidak langsung yaitu $0,157(0,537 \times 0,2940)$. Total pengaruh SPIP terhadap fraud yaitu $0,323(0,166+$ $0,157)$.

Untuk mengetahui signifkan atau tidak variabel mediasi maka dilakukan uji sobel test :

$S p 2 p 3=\sqrt{p 3^{2} S p^{2}+p 2^{2} S p 3^{2}+S p 2^{2} S p 3^{2}}$

$S p 2 p 3=\sqrt{0,294^{2} 0,176^{2}+0,537^{2} 0,166^{2}+0,176^{2} 0,166^{2}}$

$S p 2 p 3=0,107$

Berdasarkan perhitungan diatas, maka t hitung $=$

$t_{\text {hitung }}=\frac{P 2 P 3}{S p 2 P 3}$

$t_{\text {hitung }}=\frac{0,157}{0,107}$

$t_{\text {hitung }}=1,467$

$t_{\text {tabel }}=2,051$

$t_{\text {hitung }}<t_{\text {tabel }}$ maka dapat disimpulkan bahwa tidak terdapat pengaruh mediasi 
Analisis Koefisien Determinasi $\left(R^{2}\right)$

\begin{tabular}{lcccr}
\multicolumn{5}{c}{ Model Summary } \\
\hline Model & R & R Square & $\begin{array}{c}\text { Adjusted R } \\
\text { Square }\end{array}$ & $\begin{array}{c}\text { Std. Error of } \\
\text { the Estimate }\end{array}$ \\
\hline $1 \quad, 467^{a}$ &, 218 &, 160 & 4,736 \\
\hline $\begin{array}{l}\text { a. Predictors: (Constant), Total Z, Total X } \\
\text { b. Dependent Variable: Total } Y\end{array}$
\end{tabular}

Berdasarkan tabel tersebut besarnya angra $R$ square $\left(R^{2}\right)$ digunakan untuk melihat pengaruh variabel SPIP dan akuntabilitas terhadap fraud memiliki kontribusi sebesar 0,218 atau $21,8 \%$ sementara sisanya sebesar 0,782 atau $72,8 \%$ dipengaruhi oleh faktor lain seperti transparansi, partisipasi, demokrasi, aturan hukum dan efisiensi.

\section{Model Summary}

\begin{tabular}{lrrrr}
\hline Model & \multicolumn{3}{c}{$\begin{array}{c}\text { Adjusted R } \\
\text { Square }\end{array}$} & $\begin{array}{l}\text { Std. Error of } \\
\text { the Estimate }\end{array}$ \\
\hline 1 & $\mathrm{R}$ & $\mathrm{R}$ Square & \multicolumn{2}{c}{ Squar } \\
\hline
\end{tabular}

a. Predictors: (Constant), Total Y, Total $\mathrm{X}$

b. Dependent Variable: Total Z

Berdasarkan tabel tersebut besarnya angra $R$ square $\left(R^{2}\right)$ digunakan untuk melihat pengaruh variabel SPIP dan fraud terhadap akuntabilitas memiliki kontribusi sebesar 0,328 atau $32,8 \%$ sementara sisanya sebesar 0,672 atau $67,2 \%$ dipengaruhi oleh faktor lain seperti transparansi, partisipasi, demokrasi, aturan hukum dan efisiensi.

\section{Hasil dan Pembahasan}

Hipotesis pertama dalam penelitian ini adalah sistem pengendalian intern pemerintah berpengaruh positif terhadap akuntabilitas. Hasil uji parsial atau uji t pada table menunjukkan bahwa sistem pengendalian intern pemerintah berpengaruh terhadap akuntabilitas. Hal ini dapat dilihat pada hasil $t_{\text {hitung }}$ lebih besar dari tabel yaitu $0,931<2,051$ dengan nilai signifikasi 0,028 lebih kecil dari 0,05. Dengan demikian maka $\mathrm{H}_{1}$ terdukung.

Hipotesis kedua dalam penelitian ini adalah sistem pengendalian intern pemerintah berpengaruh negatif terhadap fraud. Hasil uji parsial atau uji t pada table menunjukkan bahwa sistem pengendalian intern pemerintah tidak berpengaruh terhadap fraud. Hal ini dapat dilihat pada hasil thitung lebih kecil dari $t_{\text {tabe }}$ yaitu $0,931<2,051$ dengan nilai signifikasi 0,360 lebih besar dari 0,05 . Dengan demikian maka $\mathrm{H}_{2}$ tidak terdukung.

Hipotesis ketiga dalam penelitian ini adalah sistem pengendalian intern pemerintah berpengaruh negatif terhadap fraud dengan akuntabilitas sebagai variabel mediasi. Hasil uji menunjukkan bahwa pengaruh langsung lebeh besar daripada pengaruh tidak langsung. Besarnya pengaruh langsung yaitu 0,166 , sedangkan besarnya pengaruh tidak langsung yaitu 0,157 . Kemudian dilihat dari nilai signifkan dengan uji sobel test menunjukkan bahwa nilai thitung sebesar 1,467 lebih kecil dari nilai table 2,051. Dengan demikian maka $\mathrm{H}_{3}$ tidak terdukung.

\section{Simpulan dan Saran}

Berdasarkan analisis yang dilakukan pada penelitian ini mengenai pengaruh sistem pengendalian intern pemerintah terhadap pencegahan fraud dalam pengelolaan dana desa dengan akuntabilitas sebagai variabel mediasi dapat disimpulkan bahwa: Sistem pengendalian intern pemerintah berpengaruh positif terhadap akuntabilitas hipotesis ini terdukung. Hal ini menunjukkan bahwa Peraturan Pemerintah Nomor 60 Tahun 2008 telah dilaksanakan dengan sangat baik. Sistem pengendalian intern pemerintah berpengaruh negatif terhadap fraud hipotesis ini tidak terdukung. Pencegahan fraud dengan sistem pengendalian internal belum efektif, terlalu banyak faktor yang memudahkan timbulnya kecurangan. Sistem pengendalian intern pemerintah berpengaruh negative terhadap fraud dengan akuntabilitas sebagai variabel mediasi hipotesis ini tidak terdukung. Akuntabilitas belum efektif dalam pencegahan fraud. 
Saran dalam penelitian ini bisa ditambah dengan variabel lain seperti good governance, transparansi, partisipasi dan responsibility, dapat juga ditambah dengan metode wawancara serta menambahkan jumlah sampel dan populasi

\section{Daftar Rujukan}

Adi, K., Saputra, K., Pradnyanitasari, P. D., Made, N., Priliandani, I., Gst, I., \& Putra, N. P. (2019). Manusia Untuk Pencegahan Fraud Dalam Pengelolaan Dana Desa. 10(2), 168176.

Atmadja, A. T., Adi, K., \& Saputra, K. (2015). Pencegahan Fraud Dalam Pengelolaan Keuangan Desa. 1, 7-16.

Ayu, I., Oktaviani, A., Herawati, N. T., Tungga, A., \& Ganesha, U. P. (2017). Pengaruh Paktik Akuntabilitas, Conflict Of Interest Dan Penegakan Hukum Terhadap Potensi Fraud Dalam Pengelolaan Keuangan Desa Di Kabupaten Buleleng. 1.

Buleleng, K., Gayatri, N., Yuniarta, G. A., \& Prayudi, M. A. (2017). Sistem Pengendalian Internal Terhadap Kecenderungan Terjadinya Kecurangan ( Fraud) Dalam Organisasi ( Studi Empiris Pada Organisasi Sektor Publik Di. 1(1).

Ghozali, I. (2016). Aplikasi Analisis Multivariate IBM SPSS 23.

Ina Mutmainah*, B. A. P. (2017). Akuntabilitas pengelolaan dana desa dan sistem pengendalian intern pemerintah. Subroto 2009.

Kemenkeu. (2020). Buku Saku Dana Desa.

Melisha, N. (2018). Pengaruh Aksesibilitas Laporan Keuangan, Sistem Akuntansi Keuangan Daerah, Dan Sistem Pengendalian Intern Terhadap Akuntabilitas Pengelolaan Keuangan. 1-106.

Peraturan Pemerintah 60 Tahun 2008 tentang Sisitem Pengendalian Intern Pemerintah, (2008).

Peraturan Pemerintah Nomor 29 Tahun 2014 tentang Sistem Akuntabilitas Kinerja Instansi Pemerintah, 1 (2014).

Peraturan Pemerintah Nomor 8 Tahun 2016 tentang Dana Desa yang Bersumber dari Anggaran Pendapatan dan Belanja Negara, (2016).

Riyandi, S. (2017). Jokowi sebut ada 900 kepala desa bermasalah akibat penyalahgunaan dana desa.

Undang Undang Nomor 6 Tahun 2014 tentang Desa, (2014).

Widyatama, A., \& Novita, L. (2017). Pengaruh Kompetensi dan Sistem Pengendalian Internal Terhadap Akuntabilitas Pemerintah Desa dalam Mengelola Alokasi Dana Desa ( ADD ). 02(02), 1-20.

Yudianto, I., \& Sugiarti, E. (2017). Pengaruh Penerapan Sistem Pengendalian Instansi Pemerintah (SPIP) Terhadap Akuntabilitas Pengelolaan Dana Desa. 